\title{
Institutional Research as Adjunct to University Management
}

\author{
Bernard S. Sheehan*
}

The purposes of this paper are to suggest that university management needs analytical support and to describe an office of institutional research which meets this need. Recent interest in university management has grown because institutions must plan and operate in increasingly complicated circumstances. Rapidly changing social, economic and political pressures within the universities and on the institutions from their constituencies have stressed traditoinal university administration. Taboo a few years ago, it is now widely held opinion that modern methods of management must be adapted to the universities.

Since university management is still developing, it means different things to different people. In this paper it is described by listing its functions in relation to elements of university organizational structure. The analytical support needed for these functions leads to a description of the role, operation and organization of the proposed office of institutional research (OIR).

Institutional research has eluded the attempts of many authors to define it to the satisfaction of all. John Dale Russell takes the administrative point of view that institutional research includes "studies needed for the making of important decisions about policy and procedures." 1 Nevitt Sanford places greater emphasis on research and sees institutional research as "theoretically-oriented, long-term studies of students and intensive, probably also long-term studies of the inner workings of educational institutions." 2 Rourke and Brooks contend that

... institutional research is a variegated form of organizational self-study designed to help colleges and universities gather an expanding range of information about their own internal operations and the effectiveness with which they are using their resources. ${ }^{3}$

* Dr. Bernard S. Sheban is Director of the Office of Institutional Research, University of Calgary. 
Although some form of institutional research is not new to universities, ${ }^{4}$ no definition yet has gained a concensus because institutional research is not a single area of study, nor a specific set of tools and techniques. Rather, it is better characterized by the approaches to problem-solving of its practitioners. The thesis of the following is that institutional research in the universities is the application of systems science to governance problems.

University Management

University management does not differ generically from that of any enterprise. The practice of determining and articulating goals and objectives, of formulating policies

Figure 1

University Management Functions and Organizational Structure

Typical Elements in the Organizational Structure

Functions

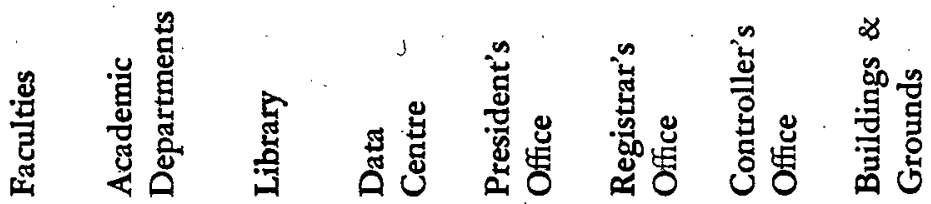

Policy

Formulation

Planning

Programming

Budgeting

Quest for

Learning

Nurture of

Learning

Transmission

Learning

Use of

Learning

Administration

Controlling

Evaluating 
and developing plans, of allocating resources for execution of programs and controlling and operating the institution and of monitoring and evaluating the results must go on in universities. What sets it apart is university organizational structure, traditions of consensus-seeking decision making, academic freedom and institutional autonomy and the difficulties in quantifying the benefits of the educational process.

Figure 1, "University Management Functions and Organizational Structure," illustrates the notions of university management salient to the operation and organization of the proposed OIR. The essential complexity of university management is demonstrated by the fact that management functions must be accomplished within the elements of the organizational structure. For example, student academic programmes involve all functions

Figure 2

Management Analytical Support

\section{MANAGEMENT FUNCTIONS}

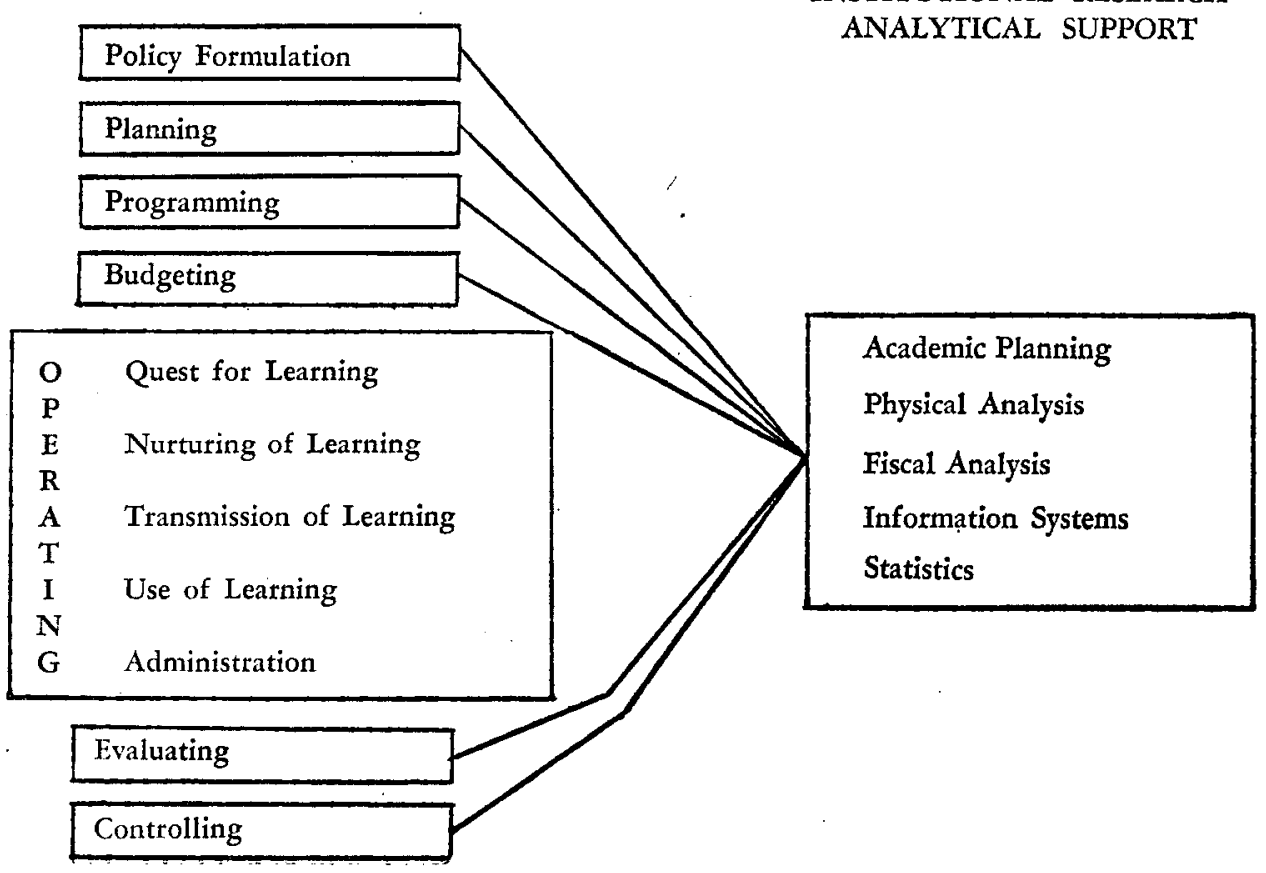

OFFICE OF

TSTITUTIONAL RESEARCH

STITUTIONAL RESEARC

Academic Planning

Physical Analysis

Statistics 
and are serviced by all elements in the operating structure. Figure 2, "Management Analytical Support," shows university management functions and the elements of the proposed OIR needed to support these functions.

The management function of administration includes the non-academic operating functions. These are those activities necessary to the running of the physical plant, daily business affairs, student admission, records and so on. The academic operating functions of quest for learning, nurturing of learning, transmission of learning, use of learning and administration are collectively termed operating functions. The proposed OIR relates directly to the other management functions and only indirectly to the operating functions. This is not to suggest that the operating functions do not require analytical support, ${ }^{5}$ and in fact much fundamental research, but only that these considerations are outside the scope of the present proposal.

\section{OIR Operations}

As viewed by analytical support staff, university management can be described by five steps: recognition of situations requiring action; explicit formulation of problems ; development of alternative solutions, including actions required and consequences of implementation; presentation of alternative solutions ; and, finally, management's understanding of solutions and acceptance of one of the alternatives. Within this framework, two styles or modes of operation span the spectrum of possible OIR activities. ${ }^{6}$ These are the active and passive modes.

The passive mode, "Statistical Data Collection," is characterized by the OIR's provision of statistical data on request and the solution of specific problems using an algorithm given by policy formulators. Successful operation in this mode builds policy formulators' confidence in the OIR; gives analysts experience in dealing with policy formulators and their problems; and leads eventually to greater involvement in the management process. The active mode, "Professional Participation," is characterized by the OIR's anticipation of information required and of problems for which the office will be asked to supply alternative solutions for the consideration of managers. Operating in this mode, the OIR can improve the efficiency of university management. It can successfully operate in this way only with the confidence of policy formulators. This confidence is maintained if the office conceives its role as being not one of policy formulation but of assisting policy makers to come quickly and assuredly to their conclusions. The OIR must be sensitive to informational needs of managers but must remain neutral in the final policy decision. Thus, the purpose of anticipation is to provide decision makers with the best information, prospect and tools so that their time and talents can most effectively be brought to bear on judgments that have to be made.

Let's consider three levels of the active mode. In Active Mode, Level 1, "Anticipation of Informational Needs," the OIR provides statistical and other information on request as in the passive mode. However, to a certain extent the request has been 
anticipated. This implies that OIR personnel are aware of the problem to be solved; understand the sensitive issues involved; and can determine important variables before an explicit request is received. This anticipation includes development of the necessary capability to retrieve the information and to formulate alternative solutions to given management problems.

Active Mode, Level 2, "Systems Initiation," also involves anticipation but differs from Level 1 in that anticipation may not be with respect to a specific solution but rather to a class or category of problems. This is an awkward level of operation because it involves initiatives on the part of the office which may not seem important to busy executives. However, because it is involved in many facets of central university administration which cross organizational boundaries, the OIR may see the need for management considerations before the need can be generally recognized. By anticipating management information needs, the office sometimes finds that it requires information which is not available. Under such circumstances, the OIR may urge development of the necessary systems to ensure that information is ready when needed.

If possible, the office should not become involved in the design, development and implementation of new systems, especially if other departments can do the job. In general, involvement beyond assisting with systems development should be avoided. Greater involvement may give the OIR vested interest in some aspect of university operations ; siphon off its resources from areas of more legitimate concern; and lead to the possibility of tensions developing between the office and operating departments concerned.

Operating in Active Mode, Level 3,. "Management Tools and Techniques," the OIR must anticipate styles of university management likely or possible in the near future. Universities are complicated, decentralized institutions, and the management decisions to be taken are as difficult as in any organization. Also, university policy formulators are usually professional scholars and teachers, and amateur managers. Thus, the OIR role in this level is to suggest, as the opportunity arises, that new tools and techniques may prove useful in solving certain problems. Since these new tools may not be familiar, the OIR may have to instruct decision makers in their potential and use. As in Level 2, the consequences of such initiatives are best understood by the senior administrative officer in the area and discussions of this sort should not be precipitated without full support.

As a consequence of the proposed theory of the role of institutional research, each office must decide how to allocate resources over a spectrum of activities ranging from academic research in higher education to meeting ad boc requests for statistical data. This is not a new dilemma ${ }^{7}$ and the unique circumstances of each university make generalized solutions difficult. The OIR must do research if it is to offer practical alternative solutions to management problems; yet it must answer some ad boc requests 
to remain in touch with current management situations and to gain or keep the confidence of university managers.

Given the situation in which universities find themselves today, it seems that offices should focus more towards the research end of the spectrum. The problems of academic planning and resource allocation need to be better understood in each institution before satisfactory solutions will be found. The state of the art in university application of such ideas as planning programming budgeting systems, management information systems and modeling are primitive. Yet, their potential to solve current management problems seems promising. To meet the need for ad boc statistical data for short-range administrative purposes, OIRs should encourage growth of analytical expertise within operating departments and senior administrative offices. People with the skills and aptitudes in operating departments are closer to the details of the particular problems and can use the resources of the OIR as required, more efficiently.

The "Interface" is an important aspect of institutional research as adjunct to university management. This facet of institutional research involves assisting university managers with the definitive formulation of specific questions to which they seek answers and then presenting answers or alternative solutions through a medium that makes the information most useful to the questioner. Figure 3 illustrates the support role cycle.

Figure 3

The Support Role Cycle

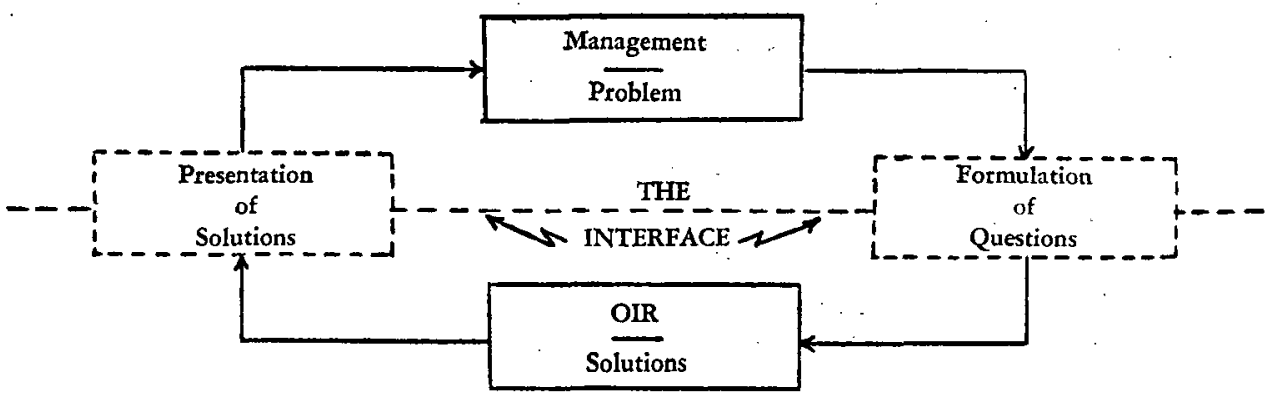

Unless there are good two-way communications between the person with the problem and the problem: solver, there is not likely to result a satisfactory solution. The OIR must develop the knack and skills of ensuring that the questioners have stated their request for information unambiguously in a way that will yield them precisely the required information of the request is exactly met. If the information or alternative 
solutions are not effectively presented, muhc of the work of the OIR can be lost. People in the OIR must develop skills - essentially teaching skills, including the use of several media - to work at the interface.

\section{OIR Organization}

The most important characteristic of the proposed OIR is that it operates as an applied research team. Projects undertaken are interdisciplinary because the office supports diverse management activities. The categories of studies done will change with time and type of institution, but since all projects relate to the informational needs of senior management, they involve considerations crossing functional and organizational lines.

Team members must be experts in the different fields of university management and competent to serve as consultants and staff personnel to the appropriate university officers and committees. Each team member is dependent on the other because all have the common purpose of supplying management information useful to the policy formulation, planning and decision making. The team must be small enough so that analysts can effectively communicate with each other, yet large enough so that the major areas of the university management are represented. Since university management can be divided into three main spheres - academic, physical and fiscal - the proposed affice should have analysts responsible for projects which are primarily within these spheres. As a consequence of the proposed theory of OIR operations, described in the previous section, the office also needs analysts expert in statistics and information systems.

Since academic policy formulation and planning is the keystone to university management, the academic planning analyst will tend to be the technical coordinator of the office. His tasks include assisting academic policy and planning committees, working with departments and faculties which seek the help of a professional planner, as well as assisting the director and analysts with interface aspects of projects. The academic, planning analyst will normally be the project leader on studies that do not fall primarily into a field of specialty of one of the other analysts.

The physical analyst is primarily concerned with space and facilities aspects of university management. He would typically do long-range and short-range space planning studies, and space, facilities and equipment inventory and utilization studies. Ideally; his main efforts would be in the development of methodologies for these studies and assisting with the improvement of the informational systems needed for space management.

The fiscal analyst's task is similar to that of the physical analyst, but in regard to the management of noncapital resources. This analyst relates to policy formulation and planning committees on fiscal and budgetary matters. He would become involved in development of methodologies and pilot studies of academic programme costs, internal 
pricing of services, implementation of planning programming budgeting systems, as well as assist with development of the necessary informational systems to support management needs for resource allocation information.

The statistician supplies the other analysts, management, and other internal and external agencies with statistical information on the university and other subjects related to higher education. This analyst is responsible for the consistency of data element definitions used within the OIR and as far as possible within the university. To avoid many requests for routine data, the statistician may prepare a Fact Book containing historical statistics on students, staff, degrees, space and finances. The statistician should also be responsible for university projections of student enrolments as requested by management and required by analysts.

The information systems analyst assists in matters related to the coordinated development of university information systems. Since university managers see the OIR as a management information system, the office has a vital interest in ensuring that management needs for information are design and operating criteria for all university information systems. Besides being an information expert, this analyst must be sensitive to the concern of the operating departments. The implementation problems associated with MIS in industry are complicated in universities because of the diffused responsibility resulting from the university's organizational structure and management traditions. He must convince the operating departments that management needs and the needs of other operating departments for information are critical to effective operation of the university.

Working with the other analysts, the information systems analyst will encourage adoption of university information system rules and procedures with respect to access, reading and writing on files, systems' design and maintenance which ensure that needs of all users, including senior management, are explicitly considered. Because of OIR interest in management information, this analyst will be concerned with the compatibility and integratibility of data from all offices or systems. It is a measure of the traditional decentralized organizational structure of universities that few, if any, other offices will have continuing interest in using information from many sources to synthesize management information.

The need for an integrated university information system will become more apparent as universities adapt more of the newer management tools and techniques to solve resources allocation problems. ${ }^{8}$ The use of models to simulate university operations is a good example. ${ }^{9}$ Even the simplest models need accurate, timely and comparable information as inputs for model runs and to set system parameters. More advanced models have not been used in universities yet; the chief technical reason for this is usually the inadequacy of the university's data base. ${ }^{10}$ Attempts to use models in university management have as their major advantage the knowledge about the institution gained in building the model. This includes the explicit, detailed knowledge of the 
inadequacies of administrative information systems. The information systems analyst will coordinate the model development work of the analysts and thus be concerned with both the interface and technical problems of modeling.

Besides describing OIR organization, the above also illustrates the professional requirements of the analysts. However, it must be emphasized that the most important characteristic of an analyst is his ability to relate his specialty to the solution of university inanagement problems, whether primarily in his field or not.

The effectiveness of the analysts is greatly increased by the technical support of assistant analysts. These junior professional should be qualified at least to a first degree in fields such as mathematics, computer science, management science, economics or engineering. Assistant analysts should not be assigned permanently to one analyst but should work on projects which utilize their talents and offer them the opportunity to learn the many facets of institutional research. As part of the team they should also have some office-wide responsibilities.

The OIR director has the dual tasks of managing the office and being the contact with the president, senior university officers, and policy formulators. Working with other senior university officers, he must decide the extent of OIR involvement in specific university management problem areas. If the office is to have its maximum long-range impact, the director needs considerable autonomy. To ensure OIR independence from special interests and thus the objectivity of its recommendations, and to protect the office from excessive ad boc requests to assist with short-range operating problems, the office should report to the chief executive. The anticipation peculiar to the active mode of operation also requires a university-wide responsibility and thus detachment from a particular sector of the university. In short, the office of institutional research should report administratively to the president and be responsible professionally through him to the university community. 
Notes

1. John Dale Russell, "Dollars and Cents: Some Hard Facts," in Higher Education: Some Newer Developments, ed. by Samuel Bashin '(New York: McGraw-Hill, 1965), Pp. 284-303.

2. Nevitt Sanford, ed., The American College (New York: John Wiley, 1962), Pp. 1027-1028.

3. Francis E. Rourke and Glenn E. Brooks, Managerial Revolution in Higher Education (Baltimore: John Hopkins Press, 1966), p. 44.

4. W. H. Cowley, "Two and a Half Centuries of Institutional Research," in College Self Study: Lectures on Institutional Research, ed. by Richard G. Axt and Hall T. Sprague (Boulder, Colorado: The Western Interstate Commission for Higher Education, 1960), pp. 1-16.

5. F. Craig Johnson, "Studying Teaching and Learning," in Institutional Research in the University: A Handbook, ed. by Paul L. Dressel and Associates (San Francisco: Jossey-Bass, 1971), pp. 125-150.

6. Bernard S. Sheehan, "The Role of Institutional Research in Support of Policy Formulation," in Institutional Research and Institutional Policy Formulation: Proceedings of Eleventh Annual Forum, ed. by Clifford T. Stewart (Association for Institutional Research, 1971).

7. Russell, "Dollars and Cents : Some Hard Facts" ; Sanford, The American College.

8. Bernard S. Sheehan, "Integrated University Management Information Systems." in Institutional Reserach and Communication in Higher Education: Proceedings of the Tenth Annual Forum, ed. by Patricia S. Wright (Association for Institutional Research, 1970), pp. 181-188.

9. Warren W. Gulko and K. M. Hussain, A Resource Requirements Prediction Model (RRPM-1): An Introduction to the Model (Boulder: National Center for Higher Education Management Systems at WICHE, 1970).

10. Colin E. Bell, "Can Mathematical Models Contribute to Efficiency in Higher Education ?" Chapter 22 in More Scholars per Dollar, Report prepared by Public Policy Research Organ. ization (Irvine: University of California, February, 1971). 